\title{
CONTRIBUCIÓN DE LAS COLONIAS DE LA BÉTICA AL PROCESO EMIGRATORIO HISPANO HACIA LAS PROVINCIAS DEL IMPERIO (SIGLOS I-II D. C.) ${ }^{1}$
}

\author{
Contribution of the Colonies of the Betica to the Hispanic Migratory \\ Process towards the Provinces of the Empire (Centuries I-II AD)
}

\author{
José Ortiz Córdoba \\ joseortiz@ugr.es \\ Universidad de Granada. España \\ Fecha de recepción: 20/02/2019 \\ Fecha de aceptación: 24/04/2019
}

Resumen: La documentación epigráfica permite conocer la existencia en época imperial de una intensa movilidad geográfica protagonizada por individuos de origen hispano. El presente trabajo tiene como objetivo principal la recopilación y estudio de la información epigráfica relativa a los movimientos emigratorios que tuvieron como origen las colonias romanas de la Bética y como destino las provincias no hispanas del Imperio. El análisis de las causas de estos desplazamientos conforma el núcleo de este trabajo y nos ha permitido establecer tres grandes grupos de emigrantes. El primero y más numeroso está conformado por los miembros del ejército; el segundo por aquellos individuos cuyo desplazamiento estuvo motivado por causas económicas y laborales; el tercero agrupa un conjunto heterogéneo de inscripciones que no permiten determinar con certeza las causas que motivaron la movilidad de sus protagonistas.

Palabras clave: emigración; movilidad; integración; colonias; Bética; Hispania.

${ }^{1}$ Ayuda puente doctores Plan Propio. Departamento de Historia Antigua, Universidad de Granada. E-mail: joseortiz@ugr.es / ORCID iD: <https://orcid.org/0000-0003-3737-1115>. Este trabajo se enmarca dentro de las líneas de estudio del grupo de investigación HUM-215 dirigido por el Prof. Dr. C. González Román y deriva de la tesis doctoral Las colonias romanas de Hispania y los movimientos de población (siglos I-Il d. C.), defendida en la Universidad de Granada en marzo de 2019. Asimismo, forma parte del proyecto de investigación Veterani et milites en las colonias romanas de Hispania, otorgado a quien suscribe estas líneas por el Plan Propio de Investigación de la Universidad de Granada en el marco del Programa de Proyectos de Investigación para Jóvenes Investigadores. 


\begin{abstract}
The epigraphic documentation allows us to know the existence in imperial time of an intense geographic mobility carried out by people of Hispanic origin. The main objective of the present work is the collection and study of epigraphic information about migratory movements that originated in the Roman colonies of Betica and that they had as destination the non-Hispanic provinces of the Empire. The analysis of the causes of this mobility forms the core of this work and has allowed us to establish three large groups of emigrants. The first and most numerous is made up of the members of the army; the second by those individuals whose displacement was motivated by economic and labor causes; the third groups a heterogeneous group of inscriptions that do not allow to determine with certainty the causes that motivated the displacements of their protagonists.
\end{abstract}

Keywords: emigration; mobility; integration; colonies; Bética; Hispania.

SUMARIO: 1. Introducción. 2. Dinámicas emigratorias. 2.1. La documentación. 2.2. Movimientos de población relacionados con el ejército. 2.2.1. Britannia. 2.2.2. Germania. 2.2.3. Pannonia. 2.2.4. Dalmatia. 2.2.5. Norte de África. 2.2.6. Italia. 2.3. Emigración relacionada con causas económicas y laborales. 2.4. Emigración sin causas determinadas. 2.4.1. Roma. 2.4.2. Norte de África. 2.4.3. Galia. 3. Conclusiones. 4. Referencias bibliográficas.

\title{
1. INTRODUCCIÓN
}

Los movimientos migratorios constituyen uno de los grandes fenómenos históricos que de forma continuada han condicionado el devenir de la Humanidad. En consecuencia, su estudio ha poseído una proyección de primer orden en las investigaciones realizadas en los diversos periodos históricos convencionalmente aceptados. En las últimas décadas hemos asistido a la publicación de numerosos trabajos relacionados con la movilidad o la emigración en época romana (a modo de ejemplos: Haley, 1986; Marín Díaz, 1988; Haley, 1991; Marco Simón, Pina Polo y Remesal Rodríguez, 2004; Caballos Rufino y Demougin, 2006; Iglesias Gil y Ruiz Gutiérrez, 2011; De Ligt y Tacoma, 2016; Ortiz Córdoba, 2019a). Todos ellos han puesto de manifiesto la complejidad y la enorme diversidad de los movimientos de población existentes en el mundo antiguo, ya que bajo esta denominación se distinguen toda una serie de tipologías que engloban desde migraciones colectivas a deportaciones forzosas, desplazamientos relacionados con el servicio militar, movilidad de tipo religioso, viajes de negocios, etc.

El Estado romano fomentó en muchos casos algunos de estos movimientos, sobre todo en lo que se refiere al desarrollo de la emigración hacia los territorios recién conquistados. En el caso hispano la plena integración de las tierras peninsulares en la nueva realidad romana favoreció, sobre todo a partir del siglo I d. C., el desarrollo de procesos emigratorios y de movilidad mediante los cuales una parte de la población hispana comenzó a proyectarse fuera de la Península Ibérica (Ortiz Córdoba, 2016, pp. 328-330). Esta dinámica, que será bastante frecuente durante el Alto Imperio, ha generado una notable producción 
bibliográfica ${ }^{2}$. La principal fuente de información para su conocimiento proviene de la documentación epigráfica. No obstante, también las fuentes literarias, aunque de forma parcial y refiriéndose sobre todo a intelectuales e individuos relevantes, nos proporcionan noticias acerca de algunos hispanos desplazados hacia el Imperio ${ }^{3}$. En estas dinámicas de carácter emigratorio jugó un papel fundamental el nuevo planteamiento imperial que pretendía superar la vieja concepción de época republicana según la cual las provincias eran vistas como un mero campo de explotación (Ortiz Córdoba, 2015, pp. 159-163).

El fenómeno de la emigración se presenta ante nosotros como un hecho complejo que afectó a amplios sectores de la sociedad hispanorromana en prácticamente todos los territorios peninsulares. Esta complejidad impide la realización de un trabajo general, por lo que hemos decidido limitar esta contribución a un marco geográfico y cronológico concreto. Desde un punto de vista geográfico nuestro estudio estará centrado en el análisis de los movimientos emigratorios que tuvieron como origen las colonias romanas de la Bética y como destino las provincias no hispanas del Imperio. Cronológicamente, nos moveremos entre los siglos I y II d. C., etapa histórica que usualmente conocemos como Alto Imperio o Principado. Esta delimitación cronológica obedece a la propia evolución histórica del mundo romano, donde los cambios protagonizados por la dinastía Severa inauguraron una etapa marcada por nuevos parámetros sociales derivados de la unificación jurídica que trajo consigo la Constitutio Antoniniana. Entre ellos se encuentra la simplificación del sistema onomástico romano, donde la mención de la origo fue decayendo progresivamente, hecho que dificulta y limita nuestro conocimiento sobre las dinámicas de movilidad existentes durante la Antigüedad tardía.

Las ciudades elegidas para realizar este estudio conforman algunos de los principales centros urbanos de la Bética. En esta provincia tenemos documentadas un total de doce colonias (Ortiz Córdoba, 2019a, pp. 97-261). La mayor parte de ellas presentan características que podríamos llamar similares, dado que fueron creadas en un periodo temporal más o menos concreto y en el marco de unas circunstancias históricas determinadas. Las mismas están marcadas por la resolución del proceso de crisis secular que conocemos con el nombre de Revolución Romana,

2 Reseñamos aquí únicamente los trabajos consultados para esta contribución: Blázquez Martínez, 1970, pp. 7-25; García Martínez, 1991, pp. 263-301; Ricci, 1992, pp. 103-143; García Martínez, 1993, pp. 321-328; García Martínez, 1994a, pp. 457-462; García Martínez, 1996, pp. 203-214; García de Castro, 1999, pp. 179-187; Ricci, 2005, pp. 267-276.

3 Uno de los más destacados fue sin duda el literato Marcial, originario de Bilbilis, a través de cuya obra Epigramma podemos conocer su estancia en Roma y el origen hispano de algunos intelectuales (Ep. I, 61). Por Suetonio conocemos también la participación de hispanos en la guardia de César (Suet., Caes., 86) y la actividad de Séneca como preceptor de Nerón (Suet., Nerón, 35). Por su parte, Plinio recoge en su obra información sobre los Cornelii Balbi, oriundos de Gades (NH., V, 36). 
cuyo desarrollo supuso la quiebra definitiva de las instituciones republicanas. La crítica moderna considera a César autor de la fundación de Hasta Regia, Hispalis, Ituci, Ucubi y Urso (Marín Díaz, 1988, pp. 202-213; González Fernández, 2005, pp. 51-52; Amela Valverde, 2016, pp. 96-109). En ellas el dictador proyectó el asentamiento de veteranos y partidarios suyos procedentes de la plebe urbana. Su vasto plan de asentamientos fue continuado en buena medida por Augusto, cuya labor colonizadora debe incardinarse en el marco de la profunda reorganización del Estado que siguió a su victoria en Actium. La trascendencia histórica de su obra quedó plasmada en las Res Gestae, donde el propio Augusto subrayó la importancia numérica de las colonias fundadas y la relevancia cuantitativa de los veteranos desmovilizados, cuyo número alcanzaría los 300.000 (Brunt, 1971, p. 341; Keppie, 1983, p. 86). En el caso de la Bética al Princeps se atribuyen las fundaciones de Tucci, Asido Caesarina, Iulia Traducta y Astigi, así como la ejecución de un segundo asentamiento de población en Corduba y Urso (García y Bellido, 1959, pp. 447-542; Brunt, 1971, pp. 259-265, 589-601 y 608-610; Keppie, 1983, pp. 41-87; González Román, 2017, pp. 349-370).

Por tanto, una buena parte de estas colonias tienen un origen militar, consecuencia directa de las deductiones de veteranos que fueron empleadas como uno de los instrumentos más eficaces para poner fin a este periodo revolucionario. Este hecho debe ser subrayado, dado que buena parte de la documentación que presentamos en este trabajo está relacionada con reclutamientos militares realizados en estas colonias. Únicamente se salen de esta pauta las ciudades de Iliturgi Forum Iulium (Mengíbar, Jaén) e Italica (Santiponce, Sevilla), cuyo acceso al rango colonial, que ha sido muy debatido en el caso de la primera, se produjo en un momento posterior y como consecuencia de unas circunstancias históricas muy distintas. Ambas ciudades conformarían lo que la historiografía ha denominado "colonias titulares», llamadas así porque su promoción jurídica se producía mediante la concesión de derechos a ciudades peregrinas, municipios romanos o colonias latinas ya existentes. Su desarrollo es característico de los reinados de Trajano y Adriano (González Román, 1981, p. 99; González Román, 1991, pp. 99-100). En el caso de lliturgi la documentación conservada apunta hacia la transformación de los municipes en coloni durante el reinado de Adriano o quizás con anterioridad (Ortiz Córdoba, 2017a, pp. 281-282). Una situación similar tuvo lugar en Italica, cuyo status municipal fue modificado por Adriano para satisfacer las demandas realizadas por los habitantes de la ciudad, hecho que sorprendió al propio emperador por su carácter inusual (Caballos Rufino, 2012, pp. 7-39).

Para el estudio de la emigración vinculada con las colonias romanas de la Bética hemos procedido a la revisión de los distintos corpora provinciales y de las diversas bases de datos informáticas existentes sobre la epigrafía latina de la Península Ibérica y de las provincias del Imperio. Dentro de las búsquedas realizadas el principal 
elemento que hemos tenido en cuenta ha sido la indicación de origo recogida en las inscripciones consultadas. Este término señala la comunidad cívica a la que está adscrita el individuo en cuestión, generalmente diferente a la del lugar de hallazgo de su inscripción. La mención de la origo indica el interés de quien la hace constar por vincularse con su patria de origen, con la que probablemente siguiera manteniendo importantes lazos afectivos y, en algunos casos, también económicos y sociales (Sobre la origo vid. Andreu Pintado, 2008, pp. 349-352; Grüll, 2018, pp. 139-150). Conviene indicar, por último, que el concepto de movilidad que hemos empleado para desarrollar este trabajo viene marcado por mostrar un carácter de migración, es decir, de permanencia en el lugar de destino, lo que lo diferencia de otro tipo de movimientos de población que implican el retorno al lugar de origen. En base a estos criterios hemos elaborado un corpus de veinticuatro inscripciones que conforma la base documental de este trabajo y que nos ha permitido extraer interesantes conclusiones acerca de las dinámicas emigratorias existentes en las colonias romanas de la Bética y su proyección hacia las provincias no hispanas del Imperio.

\section{DINÁMICAS EMIGRATORIAS}

Las causas que determinaron este tipo de movilidad pueden dividirse generalmente en tres grandes grupos: militares, político-administrativas y económicolaborales. En nuestro caso contamos únicamente con dos de estas categorías, las referidas a la movilidad militar y a la económico-laboral. No obstante, hemos detectado también un numeroso grupo conformado por aquellos individuos cuyas causas de emigración no hemos podido determinar con seguridad a partir de la información contenida en sus inscripciones. De esta manera, la muestra que a continuación detallamos aparece dividida en tres grandes bloques: movimientos de población relacionados con el ejército, emigración económico-laboral y un tercer grupo formado por aquella emigración cuyas causas no hemos podido determinar con certeza.

\subsection{La documentación}

El corpus epigráfico que presentamos en este trabajo está compuesto por un total de veinticuatro individuos procedentes de las colonias de Astigi, Corduba, Hispalis, Italica, Iulia Traducta y Tucci. Su distribución por ciudades aparece reflejada en el gráfico n. 01 . 


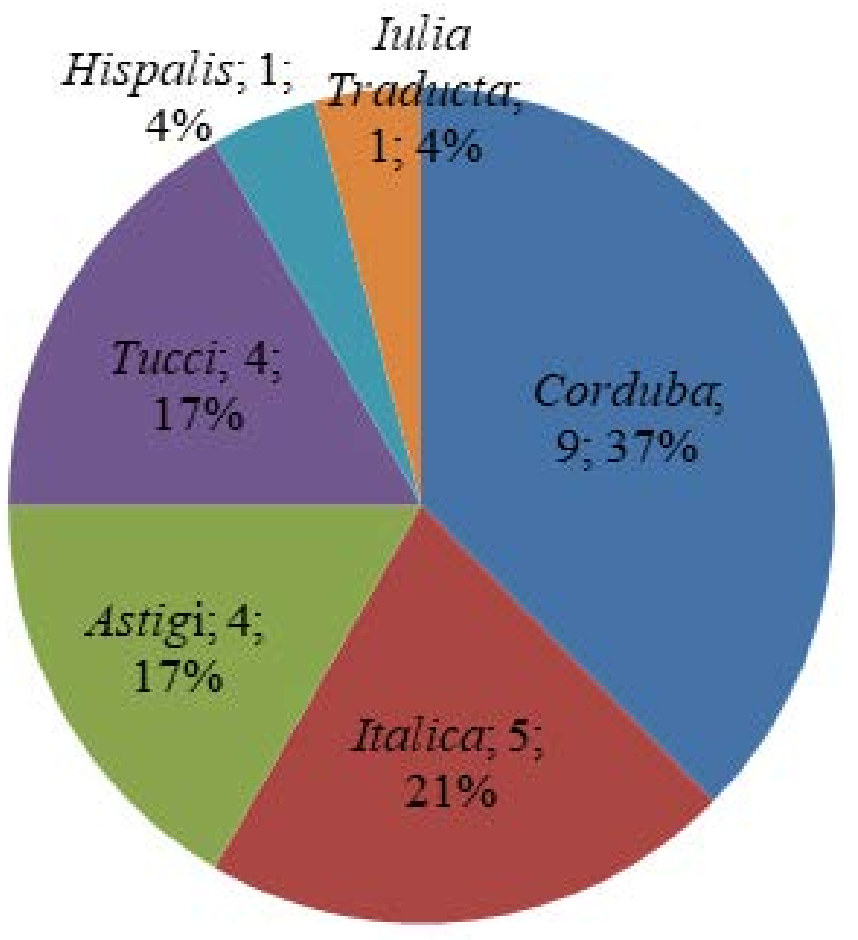

Gráfico 1. Distribución por colonias de origen de los emigrantes documentados.

Las áreas de destino se dividen en cinco grandes escenarios: Britannia, el limes renano-danubiano, Italia, el norte de África y el sur de la Galia. La región que más evidencias aporta es Italia, que cuenta con ocho testimonios; en ella el predominio de Roma como principal centro de destino es abrumador. Le siguen el limes renanodanubiano y el norte de África, con seis inscripciones cada uno. Los datos sobre la distribución de los testimonios estudiados por regiones y ciudades se encuentran resumidos en el gráfico $n$. 2 . 


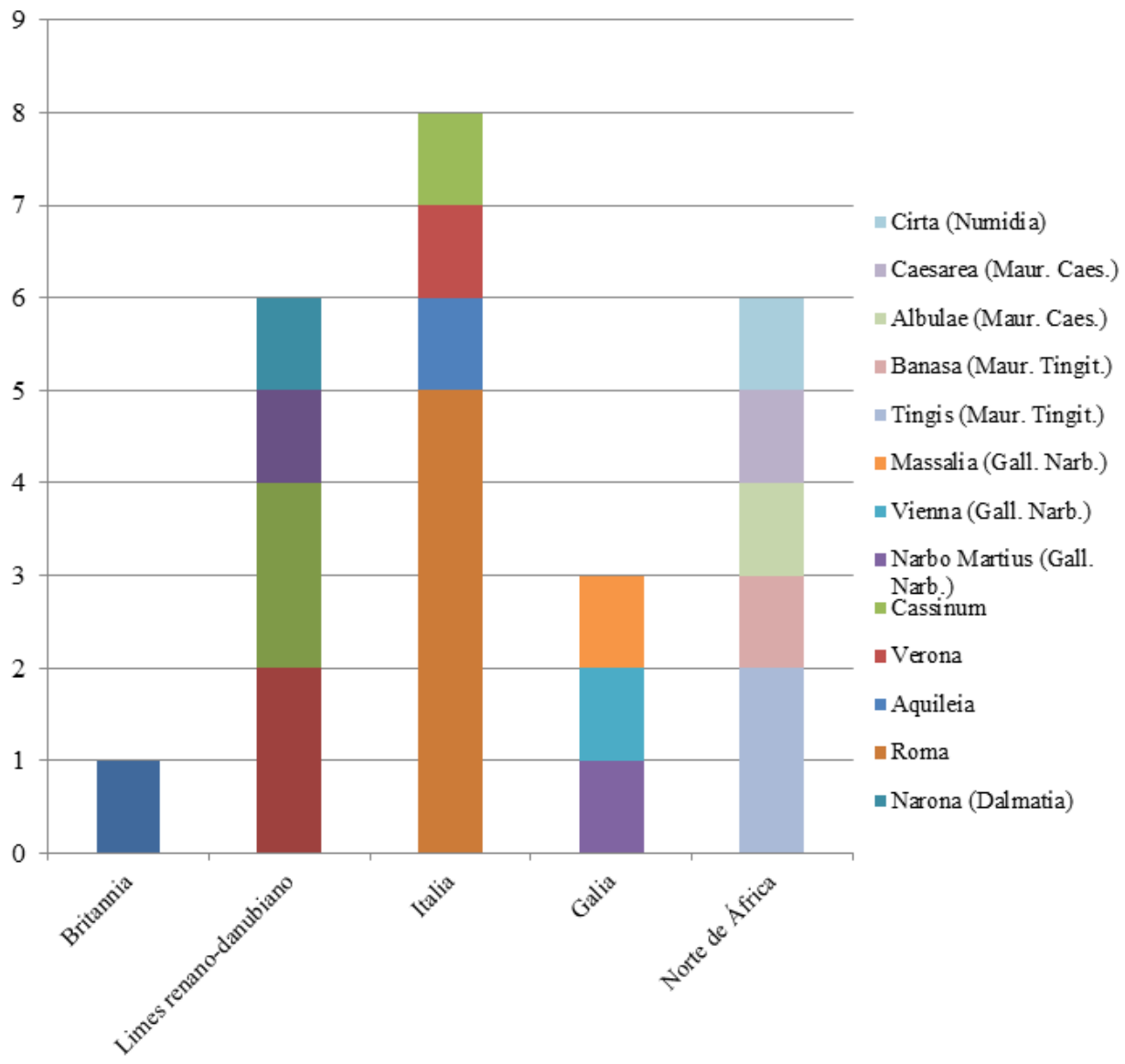

Gráfico 2. Distribución por territorios y ciudades de destino de los emigrantes documentados.

\subsection{Movimientos de población relacionados con el ejército}

El ejército constituyó durante la Antigüedad uno de los colectivos con mayor índice de movilidad. Desde época temprana tenemos constancia del empleo en el ejército romano de contingentes militares reclutados en la Península Ibérica. Su participación puede rastrearse a través del testimonio de las fuentes clásicas en enfrentamientos tan importantes como la segunda Guerra Púnica (Polibio, III, 33, 5-11; Livio, XXIV, 27, 7) o la Guerra Social, conflicto en el que tomaron parte los integrantes de la llamada de la Turma Salluitana, jinetes procedentes de la zona del Ebro a quienes Cneo Pompeyo Estrabón concedió la ciudadanía romana, según consta en el bronce de Ascoli (CIL VI, 37045) (García-Gelabert Pérez y Blázquez Martínez, 1987-1988, pp. 257-270). Esta dinámica continuará en época republicana y, sobre todo, imperial, momento en que la participación de milites de origen hispano 
en el ejército romano aumentará de forma considerable, tal y como podemos constatar a través de la documentación epigráfica ${ }^{4}$.

Una parte importante de esos contingentes militares fue reclutada en las colonias romanas de Hispania, ciudades en muchos casos de origen militar donde la continuidad del oficio castrense parece mantenerse durante un tiempo prolongado. En el caso bético uno de los ejemplos más claros de esta dinámica está constituido por Augusta Gemella Tucci, ciudad que parece mantener una especial relación con las dos unidades militares, las legiones IIII Macedonica y X Gemina, que participaron en su fundación (González Román, 2011, pp. 142-143; Ortiz Córdoba, 2017a, pp. 283-284). Para este trabajo contamos con diez personajes cuya movilidad estuvo relacionada con el ejército. Ocho de ellos se han documentado en zonas fronterizas del Imperio, mientras que los testimonios restantes proceden de las ciudades italianas de Aquileia y Verona. Estos hombres prestaron servicio en las legiones IIII Macedonica, X Gemina, I Adiutrix, XXI Rapax, XX Valeria Victrix y una última legión cuyo nombre no se ha conservado. Asimismo, documentamos una unidad de carácter auxiliar como fue la Cohors Aelia Expedita (tabla 1).

\subsubsection{Britannia}

En la isla de Britannia ha sido encontrado el epitafio de Lucius Antestius Sabinus, natural de Corduba, que habría fallecido en Deva (Chester) a finales del siglo I d. C. ${ }^{5}$. La indicación de la origo y su pertenencia a la tribu Sergia lo vinculan claramente con la capital de la Bética. Sin embargo, la pérdida del final de su epitafio nos ha privado de conocer otros datos importantes como sus años de servicio o la unidad en que los desarrolló. Este problema puede ser solventado, no obstante, a partir del lugar en el que fue encontrada su inscripción, ya que Deva conformó la sede de la Legio XX Valeria Victrix en Britannia desde época Flavia. Por ello se ha planteado tradicionalmente que nos encontraríamos ante un legionario de dicha unidad. Esta fue la postura mantenida por P. Le Roux (1982, p. 218, n.o 163),

${ }^{4}$ La participación de hispanos en el ejército romano ha sido abordada en dos trabajos ya clásicos como son las obras de J. M. Roldán Hervás (1974) y P. Le Roux (1982). En el ámbito específico de las provincias hispanas también existen diversas contribuciones para la Bética (Perea Yébenes, 1994, pp. 373-382; Morales Rodríguez, 2014, pp. 217-232; Ortiz Córdoba, 2017b, pp. 135-158), Lusitania (García Martínez, 1994b, pp. 457-462; Gutiérrez Merino, 2001, pp. 229234; Ortiz Córdoba, 2018, pp. 83-116) y la Hispania Citerior (Ortiz Córdoba, 2019b, en prensa). Algunos aspectos parciales sobre militares oriundos de la Península se encuentran incluidos también en los trabajos sobre la emigración hispana realizados por M. R. García Martínez (1991, pp. 263-302; 1994a, pp. 383-390; 1994b, pp. 457-462) y C. Ricci (1992, pp. 103-143). De forma reciente los testimonios de militares hispanos documentados en el limes septentrional han sido sistematizados por L. Hernández Guerra (2017, pp. 379-416).

${ }^{5}$ RIB, 518: L(ucius) Antesti/us L(uci filius) Serg(ia) / Sabinus / [C]ordub(a) / [---]. 
quien incluso restituyó la última línea de la inscripción como [mil(es) leg(ionis) XX V(aleriae) V(ictricis)]. Por su parte, J. Malone (2005, p. 277, n.ㅇ 113), en su obra monográfica sobre la Legio $X X$, consideró también la posibilidad de que Lucius Antestius Sabinus hubiese servido en la Legio II Adiutrix, enviada a Britannia a comienzos de la dinastía Flavia. Se basaba para ello en la temprana fecha de la inscripción. Sin embargo, la escasa presencia de hispanos en esta unidad le llevó finalmente a seguir la postura de P. Le Roux y a considerar que L. Antestius Sabinus habría formado parte de la Legio XX. Dado que esta legión fijó su campamento en Deva en época de Vespasiano, el fallecimiento de $L$. Antestius Sabinus habría tenido lugar durante los reinados de Vespasiano o Tito (Le Roux, 1982, p. 218, n.o 163).

\subsubsection{Germania}

Al igual que Britannia, la zona del Rhin conformó durante el Alto Imperio uno de los puntos clave de la frontera romana, tal y como pone de manifiesto el importante número de efectivos militares establecidos en la región. Entre ellos se encontraban diversos hispanos reclutados en las colonias de la Bética, como demuestra el hallazgo en Mogontiacum (Maguncia, Alemania), capital de Germania Superior, de las inscripciones de Quintus Bruttius Crescens, natural de Augusta Gemella Tucci ${ }^{6}$, y de Marcus Lutatius Albanus, nacido probablemente en Cordu$b a^{7}$. Ambos milites sirvieron en la Legio IIII Macedonica durante el siglo I d. C. e hicieron constar su condición de ciudadanos romanos mediante la indicación de su pertenencia a la tribu Sergia, vinculada tanto a Tucci como a Corduba (Wiegels, 1985 , pp. 30-33 y 59-60). Sus inscripciones presentan importantes paralelos en las fórmulas epigráficas empleadas: ambos indican la origo mediante el uso de la fórmula domo seguida de su ciudad natal y señalan los años de servicio con la expresión stipendia. También los datos relacionados con su edad y años de servicio son bastante similares, pues $Q$. Bruttius Crescens murió con 44 años tras 22 en activo, mientras que $M$. Lutatius Albanus lo hizo a los 40 tras haber servido durante 20. De hecho, la similar edad de ambos, así como su notable número de años en activo, indicarían que fueron reclutados durante la estancia de la legión en tierras hispanas, esto es, con anterioridad al año 40 d. C., momento en que la IIII Macedonica fue destinada al limes germano. Habría que desestimar, por tanto, las interpretaciones que han reconstruido la mención domo COR(---) presente en

${ }^{6}$ CIL XIII, 6856: Q(uintus) Bruttius / Q(uinti) f(ilius) Sergia / Crescens / domo Tucci / mil(es) leg(ionis) IIII Mac(edonicae) / ann(orum) XLIIII / stip(endiorum) XXII / h(ic) s(itus) e(st).

7 CIL XIII, 6869: M(arcus) Lutatius / M(arci) f(ilius) Ser(gia) / Albanus / dom(o) Cor(duba?) / mil(es) leg(ionis) IIII / Mac(edonicae) / annor(um) XL stip(endiorum) XX / Ven[tila]tor? h(eres) fecit. 
la inscripción de M. Lutatius Albanus como domo COR(finium), intentando asignar un presunto origen itálico a este personaje ${ }^{8}$.

También del limes germano, aunque en este caso de la vecina provincia de Germania Inferior, proceden los testimonios de Quintus Licinius Rusticus, eques de la Legio XXI Rapax nacido en Corduba ${ }^{9}$, y de Marcus Valerius Celerinus, natural de Astigi y que sirvió en la Legio $X$ Gemina $^{10}$. Ambas inscripciones fueron encontradas en Colonia Claudia Ara Agrippinensium. El primero de ellos sirvió en la Legio XXI Rapax, unidad que formó parte de la guarnición del Rhin entre los años 70 y $83 \mathrm{~d}$. C., por lo que la fecha de su inscripción puede situarse en el último tercio del siglo I d. C. Q. Licinius Rusticus falleció a los 34 años tras 14 en activo. La mención de los años de servicio permite suponer que su reclutamiento habría tenido lugar en la última etapa del reinado de Nerón (Le Roux, 1982, p. 187, n.ㅇ 62).

Una fecha similar presenta la inscripción de Marcus Valerius Celerinus, cuya condición de ciudadano romano y su vinculación con Astigi quedan claras en función de su pertenencia a la tribu Papiria. Este astigitano desarrolló su actividad militar en la Legio X Gemina, unidad para la que habría sido reclutado, según P. Le Roux (1982, p. 221, n.o 173), entre los años 68-70 d. C., momento en que la unidad aún se encontraba en Hispania. Sin embargo, en opinión de Brigitte y Hartmunt Galsterer (IKöln, 315) la fecha del reclutamiento podría adelantarse al periodo 63-69 d. C. Su carácter de militar retirado queda puesto de manifiesto en la presencia del término veteranus, que indicaría el cumplimiento de los 20 años de servicio obligatorios. Al final del mismo M. Valerius Celerinus no volvió a su tierra natal, sino que optó por asentarse en la provincia donde había sido destinada su unidad. Su integración en

${ }^{8}$ Se trata de una cuestión que ha suscitado diferentes posturas en la historiografía. La propuesta de un origen itálico es planteada en CSIR-D-02-05, 100 y seguida también por las bases digitales alemanas Epigraphik-Datenbank Clauss Slaby (EDCS) y Epigraphische Datebank Heidelberg (HD). Todos ellos apuestan por reconstruir la origo de M. Lutatius Albanus como domo Cor(finio). Por el contrario, E. Ritterling y G. Forni, siguiendo la hipótesis planteada por R. Thouvenot, consideraron Corduba como la ciudad de procedencia de este personaje. Con un origen bético se han mostrado también de acuerdo S. Perea Yébenes (1994, p. 381) y L. Hernández Guerra (2017, p. 395, n.ㅇ 9). Por su parte, tanto J. M. Roldán Hervás (1974, p. 446, n.o 516) como P. Le Roux (1982, pp. 187-188, n.ㅇ 63) presentan dudas a la hora de identificar la ciudad de origen de $M$. Lutatius, si bien el segundo de ellos parece inclinarse por la opción cordubense en virtud de los años de servicio. Según este autor los veinte años que indica $M$. Lutatius en su inscripción encajan mejor por su cronología con los hispanos que prestaron servicio en la IIII Macedonica en Mogontiacum que con los itálicos enrolados en dicha legión durante su estancia en el limes germano.

${ }^{9} A E$ 1974, 452: Q(uintus) Licinius / Q(uinti) f(ilius) Sergia / Rusticus Cord(uba) / eq(ues) leg(ionis) XXI Rap(acis) / ann(orum) XXXIIII / stip(endiorum) XIV hic / situs est h(eres) ex t(estamento) / $f$ (aciendum) [c(uravit)].

${ }_{10}$ CIL XIII, 8283: M(arcus) Val(erius) Celerinus / Papiria Astigi / cives Agrippine(nsis) / veter(anus) leg(ionis) X G(eminae) P(iae) F(idelis) / vivos fecit sibi / et Marciae Pro/cul[a]e uxori. 
la ciudad de Colonia debió ser total, ya que su inscripción recoge su reconocimiento como ciudadano de la misma -cives agrippinensis-, algo que señala con orgullo. Sin embargo, llama la atención que este personaje decidiera seguir manteniendo su tribu de origen, la Papiria, en lugar de asumir la tribu Claudia propia de los ciudadanos de Colonia. Desconocemos la causa que llevó a M. Valerius Celerinus a establecerse en su provincia de destino, aunque quizás pudo estar relacionada con el matrimonio, ya que junto a este astigitano aparece documentada también su esposa, Marcia Procula. La estela funeraria fue levantada en vida de ambos (vivos fecit) y puede fecharse con posterioridad al año $89 \mathrm{~d}$. C. por el sobrenombre Pia Fidelis que ostenta la Legio $X$. Dicho apelativo fue otorgado a esta unidad en tiempos de Domiciano por la lealtad mostrada durante el intento de usurpación de Lucio Antonio Saturnino, gobernador de Germania Superior (Rodríguez González, 2001, p. 299). Por todo ello la inscripción debería fecharse en época Flavia, como propuso P. Le Roux, o incluso en época de Trajano, como de forma más reciente se ha sugerido $(I K o ̈ / n, 315)^{11}$.

\subsubsection{Pannonia}

También del limes norte del Imperio, aunque en este caso del sector danubiano, procede el testimonio de Lucius Marcius Marcianus, documentado en Carnuntum (Pannonia Superior) ${ }^{12}$. Allí este ciudadano de Tucci fue conmemorado por un individuo de nombre desconocido que se identifica como su frater y que fue el encargado de ejecutar sus voluntades testamentarias. Lucius Marcius Marcianus murió a los 35 años tras 11 de servicio en la centuria de lustus de la Legio X Gemina. Habría sido enrolado entre los años 52 y 57 d. C., coincidiendo con la estancia de la legión en Hispania (Le Roux, 1982, p. 180, n. 29). La inscripción se fecha entre los años 63 y 68, periodo en que esta unidad estuvo asentada en el campamento fronterizo de Carnuntum (Le Roux, 1982, p. 180, n.o 29; Gómez-Pantoja y Castillo Sanz, 2014, p. 514, n.o 31). Los años de servicio aparecen señalados mediante el uso de la fórmula aera, una peculiar expresión empleada durante el siglo I d. C. por algunas unidades militares acantonadas en las provincias occidentales. Entre ellas destaca la X Gemina, la unidad de L. Marcius Marcianus (Gómez-Pantoja y Castillo Sanz, 2014, pp. 507-518).

${ }^{11}$ Quedaría descartada, por tanto, la propuesta enunciada en su día por W. Eck de fechar la inscripción en época claudiana, lo que habría hecho de Celerinus uno de los colonos fundadores de Colonia, ya que éste habría debido sobrevivir más de 50 años tras la finalización de su servicio militar (Cf. IKöln, 315).

12 AE 1929, 189: L(ucius) Marcius L(uci) / Ser(gia) Marcian/us Tucc(is) mil(es) leg(ionis) $X$ Ge(minae) / / (centuria) Iusti ann(orum) XXXV aer(um) / XI hic s(itus) e(st) s(it) t(ibi) t(erra) I(evis) / frater ex volun/tate sua f(aciendum) c(uravit). 


\subsubsection{Dalmatia}

Cerca de allí, en la zona de Dalmatia, concretamente en Narona (Croacia), ha sido documentado Quintus Mar[cius? ---], natural de Italica y que sirvió durante el siglo I d. C. en una legión cuyo nombre desconocemos ${ }^{13}$. Su papel dentro de la misma fue el de signifer, término que en las unidades de infantería romanas designaba al oficial encargado de portar el signum o estandarte de cada centuria. El estado fragmentado de la inscripción impide también conocer con seguridad sus años de vida, de los que únicamente se conservan los numerales iniciales $X X$, por lo que hemos de suponer que habrían sido 20 o más, ni tampoco los años de servicio, de los que sabemos que al menos ejerció diez en base al numeral $X$ conservado en la quinta línea.

\subsubsection{Norte de África}

En lo que se refiere al norte de África el único testimonio militar que hemos documentado procede de Albulae (Ain Temouchent, Argelia), en la provincia de Mauritania Caesariensis, donde fue encontrada la inscripción de un individuo de nombre desconocido originario de Corduba ${ }^{14}$. El epígrafe que lo documenta, que ha sido fechado en el siglo II d. C., presenta un estado muy fragmentado, lo que dificulta su lectura e interpretación. A partir de lo conservado autores como P. A. Holder o Y. Le Bohec han considerado que este cordubense habría servido en la Cohors Aelia expedita milliaria (Holder, 1998, pp. 257-258; Le Bohec, 1999, p. 122, nota 79). Esta unidad fue creada probablemente durante los reinados de Adriano o Antonino Pío en base al apelativo Aelia. Su existencia se documenta únicamente en otra ocasión más. Se trata del epígrafe de $P$. Aelius Marcianus, encontrado en Caesarea (Cherchell, Argelia), datado con posterioridad a la muerte de Adriano y donde aparece el nombre completo de la unidad ${ }^{15}$.

${ }^{13}$ CIL III, 8436: Q(uintus) MAI[- - -] / Serg(ia?) Itali[ca - - -] / signifer I[eg(ionis) XI(?) - - -] / annor(um) nat(us) XX[-- - / stipendiorum X[.

${ }^{14}$ CIL VIII, 21666: ] coh(ortis?) exp() ex VI / [- - -] aram libens / [- - -]avit CORDVB().

${ }^{15}$ CIL VIII, 9358: P(ublio) Aelio P(ubli) fil(io) Palati/na Marciano / praef(ecto) coh(ortis) I Augustae / Bracarum / praeposito n(umeri) Illyricorum / trib(uno) coh(ortis) Ael(iae) expeditae / praef(ecto) al(ae) Aug(ustae) II Thracum / praeposito al(ae) Gemin(ae) / [[Seba[sten(ae)]]] / praeposito classis / Syriacae et Augustae / praef(ecto) classis Moesiaticae / C(aius) Caesius Marcellus / veter(anus) ex dec(urione) / al(ae) II Thracum. 


\subsubsection{Italia}

Finalmente, queda por reseñar el caso de Italia, donde tenemos constatados dos testimonios procedentes de ciudades del norte de esta península. En Verona (Regio $X)$ conocemos la inscripción de Dubitatus, fallecido a los 28 años y conmemorado por su esposa Serapia ${ }^{16}$. Se desconoce la situación actual del epígrafe y carecemos igualmente de algún calco o dibujo del mismo. La única referencia que nos ha llegado de él es la incluida en CIL V, donde se proponía restituir la origo presente en la quinta línea como Astigi(tanus). La inscripción presenta varios aspectos que deben ser reseñados, si bien con la prudencia debida al analizar una inscripción de la que no se conservan imágenes. En primer lugar, resulta bastante curiosa la forma de indicación de la origo mediante la fórmula natio(ne) Astigit(anus?). Esta expresión no encuentra paralelos en Astigi, aunque sí se documenta en otras ciudades de Hispania, destacando particularmente en Corduba. Se trata de una expresión que, según J. M. Lassère (2005, pp. 132-134), aparece sobre todo en textos relativos a libertos y peregrini, habiendo sido empleada por provinciales que no eran ciudadanos romanos. Precisamente, la onomástica del homenajeado podría remitir a uno de estos estratos sociales dada su simpleza. En lo que se refiere a su profesión, L. Franzoni (1987, p. 58, n. 36) incluyó la inscripción en su obra sobre monumentos funerarios de militares en la Cisalpina aludiendo a que Dubitatus aparecía representado en la parte superior del monumento funerario portando un escudo y una espada, extremo que no podemos confirmar al carecer de imágenes. La última cuestión a reseñar es la relativa a la cronología. L. Franzoni atribuyó la inscripción a época tardía. Sin embargo, la presencia de la fórmula D.M. permitiría fecharla antes, quizás a finales del siglo II d. C. en función de la presencia del término natio (Lassère, 2005, p. 132).

La segunda inscripción procedente de Italia ha sido encontrada en Aquileia (Regio $X)$, donde conocemos a otro natural de la Bética, nacido en este caso en Italica. Se trata de Lucius Rutius Sabinus, que sirvió durante el siglo I d. C. en la Legio X Ge$m i n a^{17}$. Allí habría muerto a la edad de 50 años y tras 26 de servicio. Su fallecimiento en esta ciudad del norte de Italia podría ponerse en relación con el traslado de la Legio X Gemina desde Hispania a Carnutum y desde aquí nuevamente a Hispania en los años anteriores a la guerra civil del 69 d. C. En consecuencia, hemos de suponer que $L$. Rutius Sabinus habría muerto mientras se encontraba en activo. Los 26 años de servicio están indicados con la fórmula aera, tal y como ocurre en el caso

${ }^{16}$ CIL V, 3365: D(is) M(anibus) / Dubitato / qui vixit / annis XXVIII / natio(ne) Astigit(anus?) / [- - ] Serapi/a marito / b(ene) m(erenti).

${ }^{17}$ CIL V, 932: L(ucius) Rutius / L(uci) f(ilius) Serg(ia) / Italica / Sabinus ex / Hispania / mil(es) leg(ionis) X Gem(inae) / /(centuria) Serani / ann(orum) L / aer(orum) XXVI / hic situs est / h(eres) ex $t$ (estamento) / loc(us) mon(umenti) / in fr(onte) $p$ (edes) $X /$ in ag(ro) $p$ (edes) $X$. 
de Lucius Marcius Marcianus, tuccitano enrolado también en la Legio X Gemina. Su elevado número permite suponer que Lucius Rutius Sabinus habría sido reclutado durante la presencia de la legión en Hispania, quizás en época de Calígula o Claudio (Le Roux, 1982, p. 181, n. 34). La inscripción fue dedicada por su heredero en cumplimiento de un mandato testamentario.

\begin{tabular}{|c|c|c|c|c|c|c|c|c|c|}
\hline \multirow{2}{*}{$\begin{array}{c}\text { N.․ } \\
1\end{array}$} & \multirow{2}{*}{$\begin{array}{l}\text { Onomástica } \\
\text { Lucius } \\
\text { Antestius } \\
\text { Sabinus }\end{array}$} & \multicolumn{2}{|c|}{ Cuerpo y grado } & \multirow{2}{*}{$\begin{array}{l}\text { Fecha } \\
\text { s. I d. C. }\end{array}$} & \multicolumn{2}{|c|}{$\begin{array}{l}\text { Años de } \\
\text { servicio y } \\
\text { edad de } \\
\text { muerte }\end{array}$} & \multirow{2}{*}{\begin{tabular}{|l} 
Origen \\
$\begin{array}{c}\text { Colonia } \\
\text { Patricia }\end{array}$
\end{tabular}} & \multirow{2}{*}{$\begin{array}{c}\begin{array}{c}\text { Lugar de } \\
\text { hallazgo }\end{array} \\
\begin{array}{c}\text { Deva } \\
\text { Victrix } \\
\text { (Britannia) }\end{array}\end{array}$} & \multirow{2}{*}{$\begin{array}{c}\text { Referencia } \\
R I B, 518\end{array}$} \\
\hline & & $\begin{array}{c}\text { [Legio } \\
X X \\
\text { Valeria } \\
\text { Victrix] }\end{array}$ & [Miles] & & & & & & \\
\hline 2 & $\begin{array}{l}\text { Quintus } \\
\text { Bruttius } \\
\text { Crescens }\end{array}$ & $\begin{array}{c}\text { Legio IIII } \\
\text { Mace- } \\
\text { donica }\end{array}$ & Miles & s. I d. C. & 22 & 44 & $\begin{array}{c}\text { Augusta } \\
\text { Gemella } \\
\text { Tucci }\end{array}$ & $\begin{array}{l}\text { Mogon- } \\
\text { tiacum } \\
\text { (Germ. } \\
\text { Sup.) }\end{array}$ & $\begin{array}{l}\text { CIL XIII, } \\
6856\end{array}$ \\
\hline 3 & Dubitatus & & ¿Miles? & $\begin{array}{l}\text { ss. II-III } \\
\text { d. C. }\end{array}$ & & & Astigi & $\begin{array}{l}\text { Verona } \\
\text { (Italia) }\end{array}$ & CIL V, 3365 \\
\hline 4 & $\begin{array}{l}\text { Quintus } \\
\text { Licinius } \\
\text { Rusticus }\end{array}$ & $\begin{array}{c}\text { Legio } \\
\text { XXI } \\
\text { Rapax }\end{array}$ & Eques & s. I d. C. & 14 & 34 & $\begin{array}{l}\text { Colonia } \\
\text { Patricia }\end{array}$ & $\begin{array}{c}\text { Colonia } \\
\text { (Germ. } \\
\text { Inf.) }\end{array}$ & $\begin{array}{c}A E \text { 1974, } \\
452\end{array}$ \\
\hline 5 & $\begin{array}{l}\text { Marcus } \\
\text { Lutatius } \\
\text { Albanus }\end{array}$ & $\begin{array}{c}\text { Legio IIII } \\
\text { Mace- } \\
\text { donica }\end{array}$ & Miles & s. I d. C. & 20 & 40 & $\begin{array}{l}\text { Colonia } \\
\text { Patricia }\end{array}$ & $\begin{array}{l}\text { Mogon- } \\
\text { tiacum } \\
\text { (Germ. } \\
\text { Sup.) }\end{array}$ & $\begin{array}{c}\text { CIL XIII, } \\
6869\end{array}$ \\
\hline 6 & $\begin{array}{c}\text { Lucius } \\
\text { Marcius } \\
\text { Marcianus }\end{array}$ & $\begin{array}{l}\text { Legio } X \\
\text { Gemina }\end{array}$ & Miles & s. I d. C. & 11 & 35 & $\begin{array}{c}\text { Augusta } \\
\text { Gemella } \\
\text { Tucci }\end{array}$ & $\begin{array}{l}\text { Carnun- } \\
\text { tum (Pan. } \\
\text { Sup.) }\end{array}$ & $\begin{array}{c}A E 1929 \\
189\end{array}$ \\
\hline 7 & $\begin{array}{c}\text { Quintus } \\
\text { Mar[cius?--] }\end{array}$ & $\dot{2} ?$ & Signifer & s. I d. C. & +20 & +10 & Italica & $\begin{array}{c}\text { Narona } \\
\text { (Dalmatia) }\end{array}$ & $\begin{array}{l}\text { CIL III, } \\
8436\end{array}$ \\
\hline 8 & $\begin{array}{l}\text { Lucius Rutius } \\
\text { Sabinus }\end{array}$ & $\begin{array}{l}\text { Legio X } \\
\text { Gemina } \\
\end{array}$ & Miles & s. I d. C. & 26 & 50 & Italica & $\begin{array}{l}\text { Aquileia } \\
\text { (Italia) }\end{array}$ & CIL V, 932 \\
\hline 9 & $\begin{array}{l}\text { Marcus } \\
\text { Valerius } \\
\text { Celerinus }\end{array}$ & $\begin{array}{l}\text { Legio X } \\
\text { Gemina }\end{array}$ & $\begin{array}{c}\text { Vetera- } \\
\text { nus }\end{array}$ & s. I d. C. & & & Astigi & $\begin{array}{c}\text { Colonia } \\
\text { (Germ. } \\
\text { Inf.) }\end{array}$ & $\begin{array}{l}\text { CIL XIII, } \\
8283\end{array}$ \\
\hline 10 & $¿ ?$ & $\begin{array}{l}\text { ¿Cohors } \\
\text { Aelia } \\
\text { Expedi- } \\
\text { ta? }\end{array}$ & ¿Miles? & s. II d. C. & & & $\begin{array}{l}\text { Colonia } \\
\text { Patricia }\end{array}$ & $\begin{array}{c}\text { Albulae } \\
\text { (Maur. } \\
\text { Caes.) }\end{array}$ & $\begin{array}{l}\text { CIL VIII, } \\
21666\end{array}$ \\
\hline
\end{tabular}

Tabla 1. Auxiliares y legionarios reclutados en las colonias de la Bética. 


\subsection{Emigración relacionada con causas económicas y laborales}

La emigración de carácter económico o comercial también se encuentra representada entre los individuos recogidos en este trabajo. Se trata de un tipo de emigración cuya importancia fue en aumento a lo largo de los siglos I y II d. C. El fin de las guerras civiles, la pacificación de los mares en época de Augusto y la plena incorporación de las provincias hispanas a los circuitos comerciales romanos, posibilitaron el desarrollo de un importante comercio de exportación de productos hispanos por todo el Mediterráneo y también por una parte de la fachada atlántica (Chic García, 1994; 2006, pp. 273-299; Remesal Rodríguez, 2010). El comercio se convirtió así en un poderoso instrumento de promoción social que posibilitó la presencia de grupos comerciales hispanos en importantes puertos como Ostia y Puteoli (Remesal Rodríguez, 2004, pp. 125-136).

Esta emigración de tipo económico se encuentra representada en nuestro trabajo por dos personajes procedentes de Augusta Gemella Tucci y de Corduba. En la ciudad de Cassinum (Italia) ha sido encontrada la inscripción del Tuccitanus Marcus Gallius Fabullus. Allí falleció con tan solo 19 años en una época comprendida entre los reinados de Claudio y Trajano ${ }^{18}$. La inscripción que lo documenta recoge los honores póstumos concedidos por parte del ordo decurionum de Cassinum, que honró a este joven tuccitano con funus publicum y locus sepulturae. Desconocemos la razón de la presencia de Gallius Fabullus en esta ciudad italiana, aunque H. Solin ha propuesto relacionar su inscripción con el comercio del aceite bético, cuya presencia en el mercado romano y campano comienza a detectarse durante la primera mitad del siglo I d. C., alcanzando un gran volumen con posterioridad (Solin, 1999, pp. 445-448; Solin, 2016, pp. 210-213). Este mismo autor ha propuesto también relacionar esta inscripción con la de $P$. Petillius Colonus, otro tuccitano que ejerció en Roma como scriba aedilium curulium en época altoimperial. Ambos personajes, $P$. Petillius Colonus y M. Gallius Fabullus, están inscritos en la tribu Galeria e indican su procedencia de forma particular, pues además de su ciudad natal señalan también el nombre de su provincia precedido de la preposición ex (Caballos Rufino, 2011, pp. 185-207).

También consideramos un desplazamiento de carácter económico el protagonizado por Marcus Fabius, natural de Corduba. Se trata de un liberto trasladado desde la capital de la Bética hasta la ciudad de Narbo Martius (Gallia Narbonensis) durante el siglo I d. C. ${ }^{19}$. Las razones de este cambio de residencia debieron estar

${ }_{18}$ AE 1992, 249: M(arcus) Gallius C(ai) f(ilius) Gal(eria) / Fabullus ann(orum) XVIIII / ex Baetica Tuccitanus / huic d(ecreto) d(ecurionum) Casinatium / publice / funus et locus sepulturae /d(atus) e(st).

${ }_{19}$ AE 1916, 41: M(arco) Fabio / MMM(arcorum) I(iberto) Gi[- - -] / mercator[i - - - / [Co] rdubensi(?). 
relacionadas con el desarrollo de la actividad comercial, tal y como atestigua en la tercera línea la expresión mercator [i - - - ]. Esta indicaría, asimismo, que se trataría de un comercio a pequeña escala (García Brosa, 1999, p. 181; Wierschowski, 2001, p. 434, n.o 629). Desconocemos, sin embargo, el producto con el que fueron realizadas estas transacciones, aunque podemos pensar en el aceite bético. La presencia de este personaje en Narbo Martius, una de las ciudades más populosas del sur de la Galia, pone de manifiesto las estrechas relaciones existentes entre esta región y las ciudades de la Península Ibérica en época altoimperial, como atestiguan, por otra parte, las numerosas ánforas del tipo Dressel 20 documentadas en Narbona (Sanchez, 2002, p. 121). Dada la enorme distancia existente entre la Bética y el sur de la Galia hemos de pensar que estos contactos comerciales habrían tenido lugar por vía marítima.

También se desplazó hasta el sur de la Galia el Italicensis Lucius Marinius, cuya inscripción remite al siglo II d. C. ${ }^{20}$. El texto presenta diversos problemas de interpretación, aunque quizás podamos relacionar su movilidad con causas de tipo laboral. Este personaje fue conmemorado en Vienna (Gallia Narbonensis) por su mujer y su hijo. La inscripción presenta problemas de interpretación en relación al término grammati, situado en vertical en la parte izquierda del texto epigráfico. Podría pensarse en una abreviatura del término grammaticus o grammateus, que aludiría de esta forma a la profesión de L. Marinius. Sin embargo, no tendría sentido que este elemento tan importante dentro de la inscripción hubiese sido situado en una posición periférica de la misma, por lo que esta suposición resulta dudosa (Agusta-Boularot, 1994, p. 661; Wierschowski, 2001, p. 154, n.ㅇ 180). Por ello se ha planteado también la posibilidad de que se tratase de un supernomen (Agusta-Boularot, 1994, p. 661). Esta inscripción sería, en cualquier caso, otro ejemplo de las relaciones existentes entre la Bética y el sur de la Galia en época altoimperial.

Finalmente, resta por comentar el caso de Publius Petillius Colonus, documentado en Roma entre los siglos I-II d. C. ${ }^{21}$. Su origo no deja lugar a dudas sobre su ciudad de procedencia, la colonia Augusta Gemella Tucci (Martos, Jaén), y su onomástica puede ser relacionada asimismo con la fundación de este centro urbano, ya que su gentilicio remite a un origen itálico (Conway, 1967, p. 579) y es poco usual en Hispania (Abascal Palazón, 1994, p. 197), mientras que su cognomen, Colonus, aunque ha sido clasificado por I. Kajanto entre aquellos que hacen referencia a una profesión (Kajanto, 1982, p. 321), podría estar aludiendo realmente al propio hecho de la fundación, siendo quizás $P$. Petillius Colonus descendiente de alguno de los colonos fundadores de la ciudad. En este contexto las causas de su traslado a

20 CIL XII, 1921: Grammati // D(is) M(anibus) / L(uci) Marini / Italicensis / Sollia Annia / coniugi / karissimo / et Marinius / Claudianus / patri / pientissim(o) / et sub a(scia) ded(icaverunt).

${ }^{21}$ AE 1975, 19: P(ublio) Petillio Q(uinti) f(ilio) Ga[I(eria)] / Colono / ex provincia / Baetica Tuccitano / scribae aed(ilium) cur(ulium) / testamento / fieri iussit. 
Roma parecen poco claras. Para A. Caballos, P. Petillius Colonus pudo haber sido un escriba romano reclutado para formar parte del contingente de colonos asentados en Tucci que tras morir habría dejado estipulado en su testamento la erección en su ciudad de origen de una inscripción en su memoria. Como alternativa el propio autor afirma que también podría pensarse en un colono tuccitano que hubiese abandonado esta ciudad para desempeñar el puesto de escriba en la Urbe (CabaIlos Rufino, 2011, p. 196, nota 42). Por el contrario, H. Solin considera que la labor desarrollada por Petilius Colonus pudo haber estado vinculada con el comercio del aceite bético (Solin, 1993, p. 446), hecho que habría implicado su traslado a Italia y que permitiría relacionar su inscripción con la del también Tuccitanus $M$. Gallius Fabullus, fallecido en Cassinum, como hemos señalado anteriormente. En cualquier caso, sabemos que $P$. Petillius Colonus desarrolló en Roma la función de scriba aedilium curulium. Los escribas, cuya trascendencia en la administración romana fue aumentando a medida que esta se hacía más compleja, conformaban un grupo u ordo estructurado internamente en diversas decuriae, lo que implicaba la adquisición de una notable especialización relacionada con las competencias ejercidas por el magistrado al que servían (Muñiz Coello, 1982, pp. 16-17 y 48). Una de esas decurias era la decuria aedilicia, integrada por todos aquellos escribas que desarrollaban su oficio junto a un edil, ya fuera este plebeyo o curul, como ocurre en el caso que ahora comentamos. La pertenencia a esta decuria solía quedar reservada a personas de condición libre, hecho que debe ser reseñado ante la condición servil o liberta que presentaban buena parte de los scribae (Muñiz Coello, 1982, pp. 7 y 46). En consecuencia, podemos suponer que $P$. Petillius Colonus habría alcanzado durante su vida una cierta experiencia administrativa y gozado de una posición económica relativamente cómoda.

\begin{tabular}{|c|c|c|c|c|c|c|c|}
\hline N.ㅇ & Onomástica & Cronología & Origo & Tribu & $\begin{array}{l}\text { Lugar del } \\
\text { hallazgo }\end{array}$ & Función social & Referencia \\
\hline 11 & $\begin{array}{l}\text { Marcus } \\
\text { Fabius }\end{array}$ & Siglo I d. C. & Cordubensis & & $\begin{array}{c}\text { Narbo } \\
\text { Martius } \\
\text { (Gal. Narb.) }\end{array}$ & Mercator & $\begin{array}{c}A E \text { 1916, } \\
41\end{array}$ \\
\hline 12 & $\begin{array}{c}\text { Marcus } \\
\text { Gallius } \\
\text { Fabullus }\end{array}$ & $\begin{array}{c}\text { Entre } \\
\text { Claudio y } \\
\text { Trajano }\end{array}$ & Tuccitanus & Galeria & $\begin{array}{l}\text { Cassinum } \\
\text { (Italia) }\end{array}$ & ¿Olearius? & $\begin{array}{c}A E \text { 1992, } \\
249\end{array}$ \\
\hline 13 & $\begin{array}{l}\text { Lucius } \\
\text { Marinius }\end{array}$ & Siglo II d. C. & Italicensis & & $\begin{array}{c}\text { Vienna } \\
\text { (Gal. Narb.) }\end{array}$ & $\begin{array}{l}\text { ¿Grammaticus?; } \\
\text { ¿Grammateus? }\end{array}$ & $\begin{array}{c}\text { CIL XII, } \\
1921\end{array}$ \\
\hline 14 & $\begin{array}{l}\text { Publius } \\
\text { Petillius } \\
\text { Colonus }\end{array}$ & $\begin{array}{l}\text { Siglo I-II } \\
\text { d. C. }\end{array}$ & Tuccitanus & Galeria & Roma & $\begin{array}{l}\text { Scriba aedilium } \\
\text { curulium }\end{array}$ & $\begin{array}{c}A E \text { 1975 } \\
19\end{array}$ \\
\hline
\end{tabular}

Tabla 2. Emigración por causas económicas y laborales. 


\subsection{Emigración sin causas determinadas}

Los diez testimonios que restan por comentar pueden englobarse dentro de un tercer grupo de carácter heterogéneo en el que, por lo general, resulta bastante complicado determinar las causas que motivaron los desplazamientos de sus protagonistas. Los principales centros receptores de esta movilidad estuvieron conformados por la ciudad de Roma y el norte de África. Existe igualmente un testimonio procedente del sur de la Galia.

\subsubsection{Roma}

En el caso de la capital imperial han sido documentados cuatro emigrantes, tres de Corduba y un cuarto oriundo de Italica. En relación a la capital de la Bética conocemos los testimonios de Caius lunius Celadus, que falleció en Roma con 21 años, 5 meses y 16 días de edad ${ }^{22}$, y Baebia Venusta, muerta también en Roma a la edad de 28 años y a quien su marido, Caius Septimius Fructus, erigió una inscripción funeraria sobre una estela de mármol ${ }^{23}$. Ambas inscripciones han sido fechadas entre los siglos I y II d. C. También falleció en la capital imperial, en este caso durante el siglo I d. C., Lucius Manlius ¿Corcanus ? $^{24}$, cuya inscripción presenta algunas particularidades, ya que su reconstrucción ha suscitado distintas propuestas relacionadas con la presencia o no en el texto de la tribu Cornelia. En este sentido, el corte que sufre la primera línea, donde pueden leerse tres letras que componen la sílaba COR, ha sido interpretado por algunos autores como una abreviatura de la tribu Cornelia (Knapp, 1980, p. 61, nota 1; Wiegels, 1985, p. 31; Ricci, 1992, pp. 113-114, H.a, 10). Sin embargo, tampoco es descartable que se tratara simplemente de un problema de espacio que habría llevado a escribir el cognomen de este personaje a caballo entre las líneas 1 y 2 . De esta manera podría restituirse el cognomen Cor/canus, tal y como aparece en las lecturas recogidas en las bases de datos EDCS-23102216 y HD023918. Conviene reseñar que la restitución de la tribu Cornelia resultaría curiosa en un ciudadano procedente de Corduba, cuyos habitantes fueron inscritos en las tribus Sergia y Galeria (Wiegels, 1985, p. 30). Por otro lado, el cognomen Corcanus conforma un unicum en la epigrafía, tanto hispana como imperial. En cualquier caso, la presencia en Corduba de L. Manlius Bocchus, duumvir y praef. iur. dic. (CIL II2/7, 284), que presenta una onomástica similar a la inscripción documentada

${ }^{22}$ CIL VI, 20768: D(is) M(anibus) / C(aius) lunius / Celadus / Cordubensis / annorum XXI / mens(ium) Vd(ierum) XVI / p(ius) i(n) (!) h(ic) S(itus) e(st) s(it) t(ibi) t(erra) I(evis).

${ }^{23}$ CIL VI, 34664 y 37898: Baebia / Venusta / domo Cordub[a] / [v]ix(it) an(nos) XXVIII / C(aius) Septimius / Fructus / inpensa sua / dedit / quoquoversus p(edes) XX.

${ }^{24}$ CIL VI, 38595: L(ucius) Manlius A(uli) f(ilius) Cor/canus colonia / Patricia Corduba / in fr(onte) $p$ (edes) XII / in ag(ro) p(edes) XX. 
en Roma, podría indicar la posible existencia de un parentesco entre ambos personajes.

Finalmente, tenemos constatada en Roma la presencia de Iulia Amoena, natural de Italica y documentada en una inscripción de época augustea ${ }^{25}$. La difunta señala su procedencia mediante el empleo de la locución ex provincia Baetica y la indicación de su ciudad natal, Italica, referida en este caso como municipio. En función de su paleografía la inscripción ha sido situada en época augustea, conformando su terminus post quem la creación de la provincia Baetica (Ricci, 1992, p. 113). Esta temprana fecha concordaría también con la mención de Italica como municipium, dado que esta ciudad no alcanzó el rango colonial hasta época de Adriano.

\subsubsection{Norte de África}

En esta zona conocemos la presencia de cuatro inscripciones referidas a emigrantes desplazados desde Hispalis, Corduba, Astigi y Iulia Traducta. Dos de esos testimonios proceden de la ciudad de Tingis, actual Tánger, perteneciente a la provincia africana de Mauretania Tingitana. En esta ciudad constatamos la presencia de un emigrante procedente de Hispalis a partir de la origo Romulensis documentada en la segunda línea de su epitafio ${ }^{26}$. Sin embargo, el estado fragmentado que presenta el texto impide reconstruir su onomástica. También en Tingis ha sido documentada Valeria Bastula, natural en este caso de Corduba, que falleció a los 80 años en esta ciudad norteafricana ${ }^{27}$. El epitafio está dedicado por su hijo Valerius Severus, eq(ues) alae Gemellianae, que lo erigió como recuerdo a su madre: monumentum matri p(osuit). La presencia del Ala Gemelliana en Tingis está documentada entre los años 88 y 161 d. C. (Rhorfi, 2006, p. 392). Dado que Valeria Bastula aparece enterrada allí es de suponer que habría acompañado a su hijo cuando este fue destinado al norte de África. Por ello quizás tampoco sería descabellado proponer un origen cordubense para Valerius Severus, aunque nada en la inscripción permite confirmar tal extremo.

También de la Tingitana, en este caso de la ciudad de Banasa, procede el testimonio de Valeria Messia, originaria de Transduc(ta), ciudad que debemos identificar con la colonia bética de lulia $\operatorname{Traducta}^{28}$. Se encuentra documentada en un

${ }^{25}$ AE 1992, 153: Iunia L(uci) f(ilia) / Amoena / ex provinci[a] / Baetica municipi[o] / Italica / hic sita est / in fr(onte) p(edes) XII / in ag(ro) p(edes) XVI.

${ }^{26}$ EDCS-08800025: [D(is) M(anibus)] s(acrum) / [- - -] Romule(n)sis [- - -] / [- - ]s Aug[.

${ }^{27}$ AE 1951, 46: Valeria Bastula / Cordube(n)sis an(norum) LXXX / h(ic) s(ita) e(st) s(it) t(ibi) t(erra) I(evis) Valerius Seve/rus eq(ues) al(a)e Gemellian(a)e / monumentum matri p(osuit).

${ }_{28}$ CIL XVI, 73: M(arco) Antonio Antonif(ilio) Maximo Syro / et Valeriae Messi fil(iae) Messiae uxori eius Transduc(ta). 
diploma militar que fue otorgado en el año $122 \mathrm{~d}$. C. y donde consta que era esposa de $M$. Antonius Maximus. Desconocemos las causas de su traslado hasta el norte de África, aunque posiblemente debamos relacionar este hecho con la actividad de su esposo.

Finalmente, los dos últimos casos reunidos en este apartado hacen referencia a sendos naturales de Astigi. En Cirta (Numidia) conocemos el epitafio de Panaria, fallecida durante el siglo I d. C. ${ }^{29}$, mientras que de Caesarera (Mauretania Caesariensis) procede la inscripción de $M$. Furius Herennus, datada en el mismo periodo ${ }^{30}$. Se trata de un carmen funerario realizado sobre una estela de mármol que recoge el testimonio de este astigitano fallecido a los 50 años de edad. Varios elementos resultan interesantes en este epígrafe. El primero de ellos está conformado por la definición de $M$. Furius Herennus como hijo de veterano. Dado el carácter militar de la deductio de Astigi y la temprana fecha del epígrafe quizás podría pensarse que M. Furius Herennus fuese descendiente de alguno de los colonos fundacionales. En segundo lugar resulta curioso el motivo de su desplazamiento hasta el norte de África, pues parece que llegó a Caesarea atraído por la curiosidad y la aventura (cupidos Libuae cognoscere fines caesareae, veni cupidos). En aquella ciudad contrajo matrimonio y formó una familia (vivere dum liquit, carus meis et pius), pese a lo cual parece sentirse muy vinculado emocionalmente a su lugar de origen, pues alude poéticamente a la Bética (Baetica me genuit) y recomienda a su familia retornar a su ciudad de origen, donde posiblemente permanecían sus padres (ite mei sine me ad meos ite). Todo el carmen está impregnado de cierta nostalgia hacia el lugar de nacimiento (Arena y Bitto, 2006, p. 1026; Hamdoune, 2006, pp. 1011-1012 y 1020, n. 0 16).

\subsubsection{Galia}

El último testimonio que nos queda por reseñar es el de Etrilia Laeta, natural de Italica y documentada en Massalia en una inscripción del siglo I d. C. En ella se indica su procedencia mediante la mención de su ciudad natal y la locución ex provincia Baetica $^{31}$. Sería probablemente esposa o hija de un personaje llamado Syriacus ${ }^{32}$.

${ }^{29}$ CIL VIII, 7154: Panaria / comes / Astigita/na h(ic) s(ita) s(it) t(ibi) / t(erra) I(evis).

${ }^{30}$ CIL VIII, 21031: M(arcus) Furius Herennus Papiri(a) / Astigitan(us) veterani f(ilius) hic situs est / Baetica me genuit tel(I)us cupidus / Libuae cognoscere / cognoscere fines Caesar(e)ae / veni cupidus fata me rapuere mea / et me iacio eidus ignotis vix $\{\mathrm{s}\}$ i an/nis $L$ vivere dum liquit carus me/is et pius vix\{s\}i et in omnia sollers / ite mei sine me ad meos ite dic / rogo praeteriens hospe\{h\}s sit t(ibi) t(erra) / levis et mol(l)iter ossa quiesc(a)nt.

${ }^{31}$ CIL XII, 412: Etrilia Laeta Syriaci / ex Hispan(ia) Baet(ica) Italicensis h(ic) I(ocus) p(ublice) $d$ (atus) e(st) / M(assiliae) via Aquensi.

32 Esta parte de la inscripción ha suscitado distintas interpretaciones. En la Carte Archéologique de la Gaule (Vol. 13-03, p. 192, n.․ 62) se ha considerado que Etrilia Laeta sería 
Son desconocidas las causas que llevaron a esta mujer a desplazarse hasta el sur de la Galia, aunque quizás estuviesen relacionadas con la trayectoria profesional de Syriacus, cuya naturaleza no podemos determinar ${ }^{33}$. En cualquier caso su posición dentro de la ciudad debió ser notable, dado que su sepultura fue instalada junto a la Via Aquensis en un lugar público concedido por el ordo local.

\begin{tabular}{|c|c|c|c|c|c|c|}
\hline N.o & Onomástica & Cronología & Origo & Tribu & $\begin{array}{l}\text { Lugar del } \\
\text { hallazgo }\end{array}$ & Referencia \\
\hline 15 & $\begin{array}{l}\text { Baebia } \\
\text { Venusta }\end{array}$ & $\begin{array}{l}\text { Siglo I o II } \\
\text { d. C. }\end{array}$ & Cordubensis & & Roma & $\begin{array}{c}\text { CIL VI, } \\
34664 \text { y } \\
37898\end{array}$ \\
\hline 16 & Etrilia Laeta & Siglo I d. C. & Italicensis & & $\begin{array}{c}\text { Massalia } \\
\text { (Gal. Narb.) }\end{array}$ & CIL XII, 412 \\
\hline 17 & $\begin{array}{c}\text { Iulia } \\
\text { Amoena }\end{array}$ & $\begin{array}{c}\text { Época } \\
\text { augustea }\end{array}$ & Italicensis & & Roma & $\begin{array}{c}A E \text { 1992, } \\
153\end{array}$ \\
\hline 18 & $\begin{array}{c}\text { Caius lunius } \\
\text { Celadus }\end{array}$ & $\begin{array}{l}\text { Siglo I-II } \\
\text { d. C. }\end{array}$ & Cordubensis & & Roma & $\begin{array}{l}\text { CIL VI, } \\
20768\end{array}$ \\
\hline 19 & $\begin{array}{c}\text { Marcus } \\
\text { Furius } \\
\text { Herennus }\end{array}$ & Siglo I d. C. & Astigitanus & Papiria & $\begin{array}{c}\text { Caesarea } \\
\text { (Maur. } \\
\text { Caes.) }\end{array}$ & $\begin{array}{l}\text { CIL VIII, } \\
21031\end{array}$ \\
\hline 20 & $\begin{array}{c}\text { Lucius } \\
\text { Manlius } \\
\text { ¿Corcanus? }\end{array}$ & Siglo I d. C. & Cordubensis & ¿Cornelia? & Roma & $\begin{array}{l}\text { CIL VI, } \\
38595\end{array}$ \\
\hline 21 & Panaria & Siglo I d. C. & Astigitana & & $\begin{array}{c}\text { Cirta (Numi- } \\
\text { dia) }\end{array}$ & $\begin{array}{c}\text { CIL VIII, } \\
7154\end{array}$ \\
\hline 22 & $\begin{array}{l}\text { Valeria } \\
\text { Bastula }\end{array}$ & $\begin{array}{c}\text { Época de } \\
\text { Trajano }\end{array}$ & Cordubensis & & $\begin{array}{l}\text { Tingis } \\
\text { (Maur. } \\
\text { Tingit.) }\end{array}$ & $A E$ 1951, 46 \\
\hline 23 & $\begin{array}{l}\text { Valeria } \\
\text { Messia }\end{array}$ & 122 d. C. & Transducta & & $\begin{array}{l}\text { Banasa } \\
\text { (Maur. } \\
\text { Tingit.) }\end{array}$ & IAM II, 239 \\
\hline 24 & ¿? & & Romulensis & & $\begin{array}{l}\text { Tingis } \\
\text { (Maur. } \\
\text { Tingit.) }\end{array}$ & $\begin{array}{c}\text { EDCS- } \\
08800025\end{array}$ \\
\hline
\end{tabular}

Tabla 3. Emigración cuyas causas no pueden determinarse.

la esposa de Syriacus, mientras que para L. Wierschowski (2001, p. 109, n.o 125) se trataría de su hija.

${ }^{33}$ En relación a la misma L. Wierschowski $(2001$, p. 109, n.․ 125) ha propuesto que pudo tratarse de un comerciante, de un médico o incluso de un filósofo. 


\section{CONCLUSIONES}

La distribución geográfica de las inscripciones estudiadas constata que los principales centros receptores de esta emigración procedente de las colonias de la Bética estuvieron conformados por Roma, la frontera renano-danubiana y el norte de África. De estas regiones proceden 20 de los 24 personajes estudiados. Complementariamente, han sido encontrados también varios testimonios en Britannia y el sur de la Galia (gráfico 2). En lo que se refiere a los centros de origen, la muestra reunida nos proporciona información relativa a seis de las doce colonias existentes en la Bética. Dentro de ellas las que más testimonios aportan son Corduba, con nueve inscripciones, Italica, con cinco, y Astigi y Tucci, con cuatro casos cada una (gráfico 1).

La principal causa que propició la movilidad de los personajes estudiados fue su servicio en el ejército. Diez de los veinticuatro casos recopilados en este trabajo aluden a militares. En relación a este grupo de inscripciones podemos realizar varias consideraciones relativas a la dispersión geográfica de sus testimonios, al rango militar ostentado por sus componentes y al momento en que se produjo la muerte de estos.

a. Geográficamente, la mayoría de las inscripciones de este apartado (6 sobre 10) proceden de la frontera norte del Imperio, es decir, Britannia, Germania y Pannonia. De ellas la mayoría se concentran en la zona del Rhin, concretamente de las ciudades de Mogonticacum (Germ. Sup.) y Colonia (Germ. Inf.), donde han sido hallados cuatro de los diez testimonios incluidos en este apartado (tabla 1). La concentración de los mismos en las provincias germanas debe relacionarse con los problemas fronterizos acontecidos en la zona del Rhin durante el siglo I d. C., periodo al que remiten todas las inscripciones encontradas en esta zona.

b. En lo que se refiere a los rangos militares constatados el grupo presenta un carácter homogéneo, ya que solo uno de los personajes estudiados superó el rango de simple miles. Se trata de Quintus Mar[cius?--], natural de Italica, que fue signifer en una legión cuyo nombre no conocemos. Todos los individuos documentados sirvieron en tropas legionarias. La única excepción la conforma el testimonio de un Patriciensis de onomástica desconocida que fue enrolado en la ¿Cohors Aelia Expedita?, una de las unidades auxiliares del ejército. Finalmente, conviene señalar que todos estos soldados habrían servido a pie con la excepción de $Q$. Licinius Rusticus, que se define como eques de la XXI Rapax.

c. En relación a la trayectoria vital de estos milites la documentación reunida nos permite suponer que prácticamente todos ellos habrían fallecido mientras se encontraban en activo. Dentro de la muestra reunida contamos únicamente con el testimonio de un veteranus. Se trata de Marcus Valerius Celerinus, natural de Astigi, que optó por retirarse en Colonia tras recibir la honesta missio. Allí fue enterrado junto a su familia a finales del siglo I $d$. C. 
Frente al ejército los dos siguientes grupos de emigración que hemos definido en este trabajo resultan minoritarios. En el caso de la emigración económico-laboral hemos reunido cuatro inscripciones procedentes de Italia y el sur de la Galia. En la primera de esas regiones, concretamente en Cassinum, ha sido hallada la inscripción del Tuccitanus M. Gallius Fabullus. Su epitafio no señala las causas que motivaron su desplazamiento hasta el corazón del Imperio, aunque $\mathrm{H}$. Solin ha considerado que este personaje pudo haber estado vinculado con el comercio del aceite bético. También de Italia, aunque en este caso de su capital, procede la inscripción del también Tuccitanus $P$. Petillius Colonus, que fue scriba aedilium curulium en Roma entre los siglos I y II d. C. En la Galia, por su parte, han sido encontradas las inscripciones del Italicensis Lucius Marinius, que pudo haber sido un grammaticus, aunque sobre esto existen importantes dudas, y de Marcus Fabius, natural de Cor$d u b a$. Su epígrafe es el único que señala expresamente su participación en el ámbito comercial, dado que lo define como un mercator, es decir, como un comerciante a pequeña escala. Su presencia en Narbo Martius podría relacionarse también con el comercio del aceite bético.

Finalmente, contamos con un importante conjunto de diez inscripciones donde no podemos determinar con certeza las causas que llevaron a sus protagonistas a cambiar de domicilio. Esta movilidad tiene como principales centros de destino la ciudad de Roma y el Norte de África, donde la mayor parte de los testimonios se concentran en la Mauretania Tingitana. La presencia del elemento hispano en esta provincia africana, marcada por su carácter de frontera, estuvo estrechamente relacionada con el desarrollo de actividades militares. Estas se encuentran presentes, aunque de forma indirecta, en las inscripciones de Valeria Bastula y de Valeria Messia. La primera fue honrada en Tingis por su hijo, miembro del Ala Gemelliana; la segunda aparece mencionada en un diploma militar junto a su esposo. Sin embargo, dentro de este grupo el caso más curioso está conformado por la inscripción de M. Furius Herennus, un carmen funerario donde este personaje, natural de Astigi, afirma que se desplazó a Caesarea atraído por la curiosidad y la aventura.

En todos los casos reunidos en este trabajo la movilidad presenta un carácter definitivo. Esta circunstancia se encuentra refrendada por el hecho de que todas las inscripciones estudiadas sean de carácter funerario. En ellas se recogen, además de la onomástica del difunto, otros datos interesantes como su edad, la origo, la profesión, el nombre del dedicante y la relación familiar o de amistad que le unía con el homenajeado y otros datos complementarios como la tribu o el status jurídico, que nos aportan interesante información sobre el posición socio-económica del emigrante. La única inscripción no funeraria es el diploma militar que documenta a Valeria Messia.

En relación al componente humano de esta emigración conviene señalar que la misma estuvo protagonizada principalmente por varones, cuyos testimonios conforman el 70 \% de la documentación reunida, esto es, 17 inscripciones sobre un 
total de 24. Frente a ellos los epígrafes alusivos a mujeres son únicamente 6 , es decir, apenas un $25 \%$ de la muestra estudiada. Esta desigualdad también se refleja en relación a la posición jurídica de los individuos estudiados, donde predomina el carácter ciudadano de sus protagonistas. Únicamente el mercator M. Fabius se define claramente como liberto, condición jurídica que también podríamos hacer extensiva a L. Marinius.

Por último, conviene señalar que la documentación reunida aporta escasa información sobre la integración y el papel jugado por estos emigrantes en sus ciudades de destino, dado que solo en tres casos podemos realizar una aproximación a esta cuestión. Quizás el más interesante de todos ellos sea el del veteranus Astigitanus M. Valerius Celerinus. Este personaje, una vez desmovilizado, optó por asentarse en la ciudad germana de Colonia, donde fue admitido entre sus ciudadanos, hecho que hizo constar con orgullo en su epitafio. También debieron haber jugado un papel importante en sus comunidades de destino el Tuccitanus M. Gallius FabuIlus y la Italicensis Etrilia Laeta. El primero fue honrado por el ordo de Cassinum con la concesión de funus publicum y locus sepulturae; a la segunda le fue concedida por parte del ordo de Massalia una porción de suelo público para ser enterrada.

\section{REFERENCIAS BIBLIOGRÁFICAS}

Abascal Palazón, J. M. (1994). Los nombres personales en las inscripciones latinas de Hispania. Murcia.

Amela Valverde, L. (2016). Las colonias cesarianas del Mediodía peninsular. Una síntesis. Hispania Antiqua, 40, pp. 85-117.

Andreu Pintado, J. (2008). Sentimiento y orgullo cívico en Hispania: en torno a las menciones de origo en la Hispania Citerior. Gerión, 26(1), pp. 349-378.

Arena, M. y Bitto, I. (2006). II motivo della norte in terra straniera nei CLE bücheleriani. En A. Akerraz, P. Ruggeri, A. Siraj y C. Vismara (eds.), L'Africa romana. Mobilità delle persone e dei popoli, dinamiche migratorie, emigrazioni ed immigrazioni nelle province occidentali dell'Impero romano. Atti del XVI convegno di studio Rabat, 15-19 dicembre 2004, Vol. II (pp. 1021-1042). Roma: Carocci.

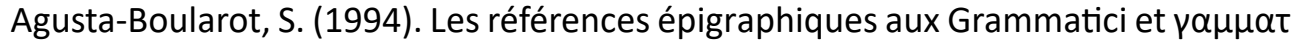
ıkoì de l'Empire romain (ler s. av. J.-C., IVe s. ap. J.-C.). Mélanges de l'Ecole française de Rome - Antiquité, École française de Rome, 106(2), pp. 653-746. 
Blázquez Martínez, J. M. (1970). Migraciones en la Hispania romana en época imperial. Anuario de Historia Económica y Social, 3, pp. 7-25.

Brunt, P. A. (1971). Italian Manpower (225 B.C.-A.D. 14). Oxford.

Caballos Rufino, A. (2011). La Bética como referente identificador en la documentación epigráfica. En A. Caballos Rufino y S. Lefebvre (eds.), Roma generadora de identidades. La experiencia hispana (pp. 185-207). Madrid: Collection de la Casa de Velázquez, 123.

Caballos Rufino, A. (2006). Colonización, integración y vertebración: El caso de Itálica. En S. Demougin y J. Scheid (eds.), Colons et colonies dans le monde romain (pp. 7-39). Roma.

Caballos Rufino, A. y Demougin, S. (eds.). (2006). Migrare. La formation des élites dans l'Hispanie romaine. Burdeos.

Chic García, G. (1994). La proyección económica de la Bética en el imperio romano (época altoimperial). Sevilla.

Chic García, G. (2006). Movimiento de personas en relación con el aceite bético. En A. Caballos Rufino y S. Demougin (eds.), Migrare: la formation des élites dans I'Hispanie romaine (pp. 273-299). Burdeos.

Conway, R. S. (1967). The italic dialects. Cambridge.

De Ligt, L. y Tacoma, L. E. (eds.). (2016). Migration and Mobility in the Early Roman Empire. Leiden-Boston.

Franzoni, C. (1987). Habitus atque habitudo militis. Monumenti funerari di militari nella Cisalpina romana. Roma.

García Brosa, G. (1999). Mercatores y negotiatores: ¿Simples comerciantes? Pyrenae, 30, pp. 173-190.

García de Castro, F. J. (1999). Hispani qui in Gallia sunt, Hispania Antiqua, 23, pp. 179-188.

García-Gelabert Pérez, M. P. y Blázquez Martínez, J. M. (1987-1988). Mercenarios hispanos en las fuentes literarias y en la arqueología. Habis, 18-19, pp. 257-270. 
García Martínez, M.a R. (1991). Caracteres y significación socio-económica de los movimientos de población hispana hacia las provincias imperiales en época romana. Hispania Antiqua, 15, pp. 263-302.

García Martínez, M.a R. (1993). Aspectos socio-profesionales y onomásticos del proceso migratorio hispano hacia las provincias imperiales en época romana, Hispania Antiqua, 17, pp. 321-328.

García Martínez, M. R. (1994a). Desplazamientos de habitantes de la Bética hacia el Imperio en época romana. En Actas del II Congreso de Historia de Andalucía. Córdoba, 1991 (pp. 383-390). Córdoba.

García Martínez, M.a R. (1994b). Contribución de la provincia Lusitania al movimiento de población hispana hacia las provincias imperiales en época romana. En S. Ordóñez Agulla y P. Sáez Fernández (coords.), Homenaje al profesor Presedo (pp. 457-462). Sevilla.

García Martínez, M. a R. (1996). Evidencias epigráficas de población hispana en la Gallia de época la época romana. Memorias de Historia Antigua, 17, pp. 203214.

García y Bellido, A. (1959). Las colonias romanas de Hispania, Anuario de historia del derecho español, 29, pp. 447-512.

Gómez-Pantoja, J. L. y Castillo Sanz, F. J. (2014). Una fórmula epigráfica fracasada: aera. En F. Cadiou y M. Navarro Caballero (eds.), La guerre et ses traces (pp. 507-518). Burdeos.

González Fernández, J. (2005). Colonización y latinización en la Hispania Ulterior Baetica. Anejos de AEspA, 34, pp. 43-56.

González Román, C. (1981). Imperialismo y romanización en la provincia Hispania Ulterior. Granada.

González Román, C. (1991). Las colonias romanas de la Hispania meridional en sus aspectos socio-jurídicos. En C. González Román (coord.), La Bética en su problemática histórica (pp. 87-110). Granada.

González Román, C. (2011). Colonia Augusta Gemella Tucci. En J. González Fernández y J. C. Saquete Chamizo (eds.), Colonias de César y Augusto en la Andalucía Romana (pp. 129-165). Roma, 2011. 
González Román, C. (2017). Augusto y las colonias de la Hispania meridional. Gerión, 35(n. o extra 0, ejemplar dedicado a la Hispania de Augusto), pp. 349-370.

Grüll, T. (2018). Origo as identity factor in Roman epitaphs. En G. Cupcea y R. Varga (eds.), Social Interactions and Status Markers in the Roman World (pp. 139150). Oxford.

Gutiérrez Merino, J. C. (2001). La presencia de hispanos en la provincia romana de Britannia a través de las fuentes epigráficas. En Actas del I Congreso Internacional de Historia Antigua. La Península Ibérica hace 2000 años. Valladolid, 23-25 de noviembre de 2000 (pp. 229-234). Valladolid.

Haley, E. W. (1986). Foreigners in Roman Imperial Spain: investigations of geographical mobility in the spanish provinces of the Roman Empire (30 B.C. A.D. 284). Columbia University.

Haley, E. W. (1991). Migration and economy in Roman Imperial Spain. Barcelona.

Hamdoune, C. (2006). Mouvements de population dans les carmina funéraires africains. En A. Akerraz, P. Ruggeri, A. Siraj y C. Vismara (eds.), L'Africa romana. Mobilità delle persone e dei popoli, dinamiche migratorie, emigrazioni ed immigrazioni nelle province occidentali dell'Impero romano. Atti del XVI convegno di studio Rabat, 15-19 dicembre 2004, Vol. II (pp. 1001-1020). Roma: Carocci.

Hernández Guerra, L. (2017). Movilidad geográfica. Auxiliares y legionarios hispanos con mención de origo en el limes septentrional del Imperio. En J. J. Ferrer Maestro, C. Kunst, D. Hernández de la Fuente y E. Faber (eds.), Entre los mundos: Homenaje a Pedro Barceló (pp. 379-416).

Holder, P. A. (1998). Auxiliary units entitled Aelia. ZPE, 122, pp. 253-262.

Iglesias Gil, J. M., y Ruiz Gutiérrez, A. (eds.). (2011). Viajes y cambios de residencia en el mundo romano. Santander.

Kajanto, I. (1982). The Latin cognomina. Roma.

Keppie, L. (1983). Colonisation and veteran settlement in Italy. 47-14 b.C. Roma.

Knapp, R. (1980). La epigrafía y la historia de la Córdoba romana. Anuario de Filología, 6, pp. 61-72. 
Lassère, J. M. (2005). Manuel d'Épigraphie Latine.

Le Bohec, Y. (1999). Frontières et limites militaires de la Maurétanie Césarienne sous le Haut-Empire. En C. Lepelley et X. Dupuis (eds.), Frontières et limites géographiques de l'Afrique du Nord Antique. Hommage à P. Salama. Acres de la table ronde (2-3 mai 1997, Paris) (pp. 111-127). París.

Le Roux, P. (1982). L'armée romaine et l'organisation des provinces iberiques d'Auguste a l'invasion de 409. París.

Malone, J. (2005). Legio XX Valeria Victrix a prosopographical and historical study. Nottingham.

Marco Simón, F., Pina Polo, F., y Remesal Rodríguez, J. (eds.). (2004). Vivir en tierra extraña. Emigración e integración cultural en el mundo antiguo. Actas de la reunión realizada en Zaragoza los días 2 y 3 de junio de 2003. Barcelona.

Marín Díaz, M.a A. (1988). Emigración, colonización y municipalización en la Hispania republicana. Granada.

Morales Rodríguez, E. M.a (2014). Epigrafía legionaria en el Alto Guadalquivir. En G. Bravo y R. González Salinero (eds.), Conquistadores y conquistados: relaciones de dominio en el mundo romano (pp. 217-232). Madrid.

Muñiz Coello, J. (1982). Empleados y subalternos de la administración romana. I. Los scribae. Huelva.

Ortiz Córdoba, J. (2015). Pax et migratio: los beneficios de la Pax Romana para el fenómeno migratorio en la península ibérica. En J. López Vilar (ed.), Tarraco Biennal. 2 Congrés Internacional d'Arqueologia i Món Antic August i le s províncies occidentals 2000 anive rsari de la mort d'August (pp. 159-163). Tarragona.

Ortiz Córdoba, J. (2016). Emigración y exilio en Roma: de las Guerras Civiles al Alto Imperio. En G. Bravo y R. González Salinero (eds.), Crisis en Roma y soluciones desde el poder (pp. 313-336). Madrid.

Ortiz Córdoba, J. (2017a). Colonización y emigración en el Alto Guadalquivir (Siglos I a. C.- II d. C.). Espacio, Tiempo y Forma. Serie II, Historia Antigua, 30, pp. 271-298. 
Ortiz Córdoba, J. (2017b). Reclutamientos y unidades militares en las colonias de la Hispania Meridional. Florentia lliberritana, 28, pp.135-158.

Ortiz Córdoba, J. (2018). Reclutamiento y unidades militares en las colonias romanas de Lusitania. Studia Historica. Historia Antigua, 36, pp. 83-116.

Ortiz Córdoba, J. (2019a). Las colonias romanas de Hispania y los movimientos de población. Granada, Universidad de Granada. Tesis Doctoral.

Ortiz Córdoba, J. (2019b). Reclutamiento y unidades militares en las colonias romanas de la Hispania Citerior. Gladius, 39, en prensa.

Perea Yébenes, S. (1994). La Bética emisora y receptora de soldados legionarios durante el Alto Imperio romano. En Actas del II Congreso de Historia de Andalucía. Córdoba, 1991 (pp. 373-382). Córdoba.

Remesal Rodríguez, J. (2004). Promoción social en el mundo romano a través del comercio. En J. Remesal Rodríguez, F. Marco Simón y F. Pina Polo (eds.), Vivir en tierra extraña: emigración e integración cultural en el mundo antiguo: actas de la reunión realizada en Zaragoza los días 2 y 3 de junio de 2003 (pp. 125-136). Barcelona.

Remesal Rodríguez, J. (1992). De Baetica a Germania, consideraciones sobre la ruta y el comercio atlántico en el Imperio Romano. En F. Marco Simón, F. Pina Polo y J. Remesal Rodríguez (eds.), Viajeros, peregrinos y aventureros en el mundo antiguo (pp. 147-160). Barcelona.

Ricci, C. (1992). Hispani a Roma. Gerión, 10, pp. 103-143.

Ricci, C. (2005). Ispanici a Roma nel II secolo. La componente militare. En Actas del II Congreso Internacional de Historia Antigua: la Hispania de los Antoninos (98-180) (pp. 267-276). Valladolid.

Rodríguez González, J. (2001). Historia de las legiones romanas. Madrid.

Roldán Hervás, J. M. (1974). Hispania y el ejército romano. Salamanca.

Rrhorfi, A. (2006). Les traits majeurs de l'immigration romaine en Tingitane. En A. Akerraz, P. Ruggeri, A. Siraj y C. Vismara (eds.), L'Africa romana. Mobilità delle persone e dei popoli, dinamiche migratorie, emigrazioni ed immigrazioni nelle province occidentali dell'Impero romano. Atti del 
XVI convegno di studio Rabat, 15-19 dicembre 2004, Vol. I. (pp. 383401). Roma: Carocci.

Sanchez, C. (2002). Au carrefour des influences méditerranéennes et continentales. Le rôle de Narbonne dans le commerce Antique. En CAG 11/1. Paris (pp. 117-123). París: Académie des Inscriptions et BellesLettres.

Solin, H. (1999). Un tuccitano a Cassino. En M. Mayer y J. Gómez Pallarés (coords.), Religio deorum: actas del coloquio internacional de epigrafía "Culto y sociedad en Occidente» (pp. 445-448). Sabadell: Ausa.

Solin, H. (2016). Nuove iscrizioni da Cassino. En H. Solin (a cura di), Le epigrafi della Valle di Comino: atti del dodicesimo convegno epigrafico cominese: Atina, Palazzo Ducale, 29-30 maggio 2015 (pp. 210-213).

Wiegels, R. (1985). Die Tribusinschriften des romischen Hispanien. Berlín.

Wierschowski, L. (2001). Fremde in Gallien - "Gallier» in der Fremde. Die epigraphisch bezeugte Mobilität in, von und nach Gallien vom 1. bis 3. Jh. n. Chr. Stuttgart. 